\title{
Seletividade de herbicidas aplicados com óleo mineral na cultura da mandioca 'Cascuda' ${ }^{1}$
}

\section{Selectivity of herbicides applied with mineral oil in cassava 'Cascuda'}

Neumarcio Vilanova Costa ${ }^{2}$; Guilherme Cardoso Pavan ${ }^{3}$; Rodrigo Fernando Dourado ${ }^{3}$; Andreia Cristina Peres Rodrigues da Costa ${ }^{4}$; Edmar Soares Vasconcelos ${ }^{2}$

Resumo - O uso de adjuvante pode influenciar na seletividade dos herbicidas as culturas agrícolas. Objetivou-se avaliar a seletividade de herbicidas aplicados com diferentes concentrações de adjuvante óleo mineral na cultura da mandioca 'Cascuda'. O delineamento experimental utilizado foi o de blocos ao acaso, com quatro repetições. Foi utilizado o esquema fatorial $3 \times 3+1$ que consistiu de três herbicidas clethodim $\left(120 \mathrm{~g} \mathrm{ha}^{-1}\right)$; fluazifop-p-butyl $(250 \mathrm{~g}$

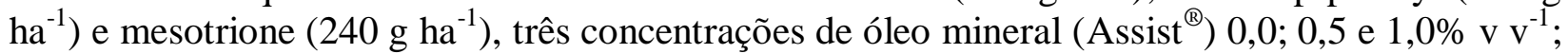
além de uma testemunha sem aplicação. Todas as parcelas foram mantidas livres da interferência das plantas daninhas por meio de capinas manuais. Apenas, o mesotrione promoveu sintomas de fitointoxicação leves a moderados (5,5 a 51,3\%) quando aplicado com óleo mineral. Contudo, todos os herbicidas apresentaram-se seletivos à mandioca 'Cascuda' na dose aplicada, tanto na presença quanto ausência de óleo mineral até $1 \% \mathrm{v} \mathrm{v}^{-1}$.

Palavras-chaves: Manihot esculenta, plantas daninhas, controle químico, adjuvante

Abstract - The use of adjuvant can influence the selectivity of herbicides on crops. Aimed to evaluate the selectivity of herbicides with different concentrations of mineral oil adjuvant in cassava 'Cascuda'. The experimental design was a randomized block design with four replications. We used a factorial design $3 \times 3+1$ which consisted of three herbicides clethodim (120 $\left.\mathrm{g} \mathrm{ha}^{-1}\right)$, fluazifop-p-butyl $\left(250 \mathrm{~g} \mathrm{ha}^{-1}\right)$ and mesotrione $\left(240 \mathrm{~g} \mathrm{ha}^{-1}\right)$, three concentrations of mineral oil $\left(\right.$ Assist $^{\circledR}$ ) $0.0,0.5$ and $1.0 \% \mathrm{v} \mathrm{v}^{-1}$, and a control without application. All plots were kept free of weed interference by hand weeding. Only the mesotrione promoted phytointoxication mild to moderate (5.5 to $51.3 \%$ ) when applied with mineral oil. However, all herbicides were selective for cassava plants 'Cascuda' in applied both in the presence and absence of mineral oil to $1 \% \mathrm{v} \mathrm{v}^{-1}$.

Keywords: Manihot esculenta, weeds, chemical control, adjuvant

\footnotetext{
${ }^{1}$ Recebido para publicação em 08/02/2013 e aceito em 05/02/2014.

2 Docentes do Centro de Ciências Agrárias da Universidade Estadual do Oeste do Paraná (Unioeste), Rua Pernambuco, C.P. 91, CEP: 85960-000, Marechal Cândido Rondon, PR. Email: <neumarcio.costa@unioeste.br>. (Autor para correspondência).

${ }^{3}$ Discentes do curso de Agronomia Universidade Estadual do Oeste do Paraná (Unioeste).

4 Docente do Centro de Ciências Agrárias da Universidade Estadual de Maringá, Estrada da Paca, Bairro São Cristóvão, CEP: 87507-190, Campus Regional de Umuarama, PR.
} 


\section{Introdução}

A mandioca (Manihot esculenta Crantz) tem a sua origem no Brasil sendo cultivada em mais de 90 países, caracteriza-se por ser uma planta tolerante a condições de seca e baixa fertilidade do solo, sendo comumente cultivada e consumida por pequenos produtores rurais em áreas com solos pobres, e onde as condições climáticas são constantemente desfavoráveis à exploração de outras culturas (Doretto, 1993; Sagrilo et al., 2002). Entretanto, além da cultura atender a agricultura de subsistência ou processamento mínimo, também se destaca a industrialização em grande escala, principalmente com as fecularias do Centro-Sul do país (Felipe et al., 2010).

Segundo a última estimativa da FOOD AND AGRICULTURE ORGANIZATION OF THE UNITED NATIONS (FAO) realizada em 2009, a Nigéria apresentou-se como o maior produtor mundial de mandioca com participação de $15,7 \%$ da produção total, seguida da Tailândia com 12,9\% e do Brasil com 10,4\% (FAO, 2011). No Brasil o Estado do Paraná destaca-se dentre os principais produtores de mandioca, com área cultivada em torno de 179,6 mil hectares e produção de 4,1 milhões de toneladas de raízes na safra 2011/2012, com produtividade média de 22,6 t ha $^{-1}$ (IBGE, 2012). A maior parte da produção de mandioca do Paraná destina-se a indústria de fécula e farinha, sendo as variedades Fécula Branca, Baianinha e Cascuda as mais plantadas. Contudo, apesar da produtividade da mandioca no Estado do Paraná ser 55,9\% superior à média nacional (14,5 $\left.\mathrm{t} \mathrm{ha}^{-1}\right)$, encontra-se ainda, aquém do potencial produtivo da cultura, devido principalmente a interferência causada pelas plantas daninhas, ao emprego de práticas de manejo inadequadas ou pouco eficientes (Silva et al., 2009).

Vários pesquisadores verificaram que a convivência da comunidade de plantas daninhas com a cultura da mandioca pode reduzir a produção de raízes em 89,8 a $100 \%$
(Peressin et al., 1998; Alabi et al., 2001; Chikoye et al., 2001; Johanns \& Contiero, 2006; Albuquerque et al., 2008; Biffe et al., 2010). Na cultura da mandioca, os principais métodos de manejo de plantas daninhas utilizados são o controle manual, por meio de capinas com enxadas; o mecânico, com auxílio de cultivadores e o químico, por meio da aplicação de herbicidas. Entretanto, devido a escassez da mão de obra destinada às capinas manuais, dos danos as raízes da cultura causados pelos cultivadores, além do baixo rendimento no controle, estes métodos estão sendo pouco utilizados em áreas de lavouras comerciais, além de que, podem apresentar custo 22 a $64 \%$ superior em relação ao controle químico ou ao manejo integrado (Chikoye et al., 2006; Silva \& Chabaribery, 2006). Desta maneira, o controle químico apresenta-se como excelente alternativa para o manejo das plantas daninhas na cultura da mandioca por permitir a intervenção em grandes áreas com pouca dependência de mão de obra e rapidez na aplicação (Silva et al., 2012; Silveira et al., 2012).

No Brasil, dos cinco herbicidas registrados para a cultura da mandioca (ametryna+clomazone, clethodim, clomazone, isoxaflutole e metribuzin) apenas o clethodim está registrado para uso em pós-emergência, sendo recomendado para o controle de gramíneas anuais e perenes (Rodrigues \& Almeida, 2011). No entanto, Silva et al. (2012) relataram que existem diversas moléculas de herbicidas que possibilitaram resultados de pesquisa satisfatórios no controle das plantas daninhas, sendo seletivos para a mandioca, porém ainda estão sem registro. Entre esses produtos destacam-se o fluazifop-p-butil e o mesotrione que apresentaram seletividade a mandioca, e que podem ser incluídos em programas de manejo de plantas daninhas (Oliveira Jr. et al., 2001; Chikoye et al., 2006; Silva et al., 2011; Silveira et al., 2012).

Apesar do controle químico apresentar vantagens sobre os demais métodos de controle 
de plantas daninhas, ressalta-se que deve ser praticado com o uso de herbicidas seletivos para a cultura. Segundo Velini et al. (2000a), para ser recomendado de forma definitiva e indiscriminada para uma determinada cultura, um herbicida deve demonstrar seletividade aos cultivares mais comuns dessa cultura. Esses autores definem seletividade como a capacidade de um determinado herbicida em eliminar as plantas daninhas encontradas em uma cultura sem reduzir-lhe a produtividade.

Usualmente em aplicações de herbicidas em pós-emergência, recomenda-se acrescentar adjuvantes à calda de pulverização. Estes produtos podem aumentar a deposição das gotas nas plantas daninhas e a molhabilidade da superfície foliar, devido a redução da tensão superficial e do ângulo de contato da gota, o que consequentemente, aumenta a penetração cuticular e a absorção do ingrediente ativo pela planta (Buick et al., 1993; Singh \& Mack, 1993; Stock \& Holloway, 1993; Mendonça et al., 2007). Desta forma, o aumento na deposição de gotas e da absorção pode proporcionar melhores níveis de controle das plantas daninhas e contribuir para a redução da dose do herbicida (Souza et al., 2007; Maciel et al., 2010). Em contra partida, a tolerância da cultura ao herbicida pode ser reduzida pela a ação dos adjuvantes, uma vez que, a determinação da seletividade pode ser dependente da dose absorvida do herbicida e da capacidade da planta em metabolizar o ingrediente ativo. Assim, objetivou-se avaliar a seletividade de herbicidas aplicados com diferentes concentrações de adjuvante óleo mineral na cultura da mandioca 'Cascuda'.

\section{Material e Métodos}

O experimento foi instalado na Estação Experimental do IAPAR em Porto Mendes/PR distrito de Marechal Cândido Rondon/PR. A área foi anteriormente cultivada com milho (semeadura em março/2011) no espaçamento de $0,7 \mathrm{~m}$ entre linhas com 3,5 plantas por metro. Após a colheita do milho realizou-se a dessecação da área (setembro/2011) utilizandose o glyphosate (ZAPP Qi 620), na dose $2 \mathrm{~L} \mathrm{ha}^{-1}$ do produto comercial.

$\mathrm{O}$ delineamento experimental utilizado foi o de blocos ao acaso, com quatro repetições. Foi utilizado o esquema fatorial $3 \times 3+1$ que consistiram em três herbicidas clethodim (120 $\left.\mathrm{g} \mathrm{ha}^{-1}\right)$; fluazifop-p-butyl (250 $\left.\mathrm{g} \mathrm{ha}{ }^{-1}\right)$ e mesotrione $\left(240 \mathrm{~g} \mathrm{ha}^{-1}\right)$, três concentrações de óleo mineral (Assist ${ }^{\circledR}$ ) 0,0 ; 0,5 e $1,0 \% \mathrm{v} \mathrm{v}^{-1}$; além de uma testemunha sem aplicação. As parcelas foram constituídas de 5 linhas de 7,0m e espaçamento de $0,9 \mathrm{~m}$ entre plantas. Durante a condução do experimento todas as parcelas foram mantidas livres da interferência das plantas daninhas por meio de capinas manuais.

O plantio da variedade 'Cascuda' foi realizado em 15/09/2011, com auxílio de plantadora mecanizada em linha no espaçamento de 0,9 x $0,7 \mathrm{~m}$. As manivas utilizadas apresentavam $12 \mathrm{~cm}$ de comprimento, contendo de 7 a 9 gemas e foram obtidas na área de produção do campo experimental do IAPAR.

O solo foi preparado utilizando uma aração e duas gradagens, sendo que a análise química apresentou as seguintes características: $\mathrm{pH}\left(\mathrm{CaCl}_{2}\right)=5,6$; matéria orgânica $\left(\mathrm{g} \mathrm{dm}^{-3}\right)=$ 22,6; $\mathrm{P}\left(\mathrm{mg} \mathrm{dm}^{-3}\right)=4,0 ; \mathrm{H}+\mathrm{Al}, \mathrm{K}, \mathrm{Ca}, \mathrm{Mg}, \mathrm{SB}$ e CTC $\left(\mathrm{cmol}_{\mathrm{c}} \mathrm{dm}^{-3}\right)=4,61 ; 0,51 ; 8,09 ; 1,88$; 10,48 e 15,09; respectivamente; e V\% $=69,45$; tendo em sua composição textural 15,0 \% de areia; $30,0 \%$ de silte e $55,0 \%$ de argila. Os dados de temperatura média $\left({ }^{\circ} \mathrm{C}\right)$ e de precipitação $(\mathrm{mm})$ durante $\mathrm{o}$ período de condução do experimento estão descritos na Figura 1. 


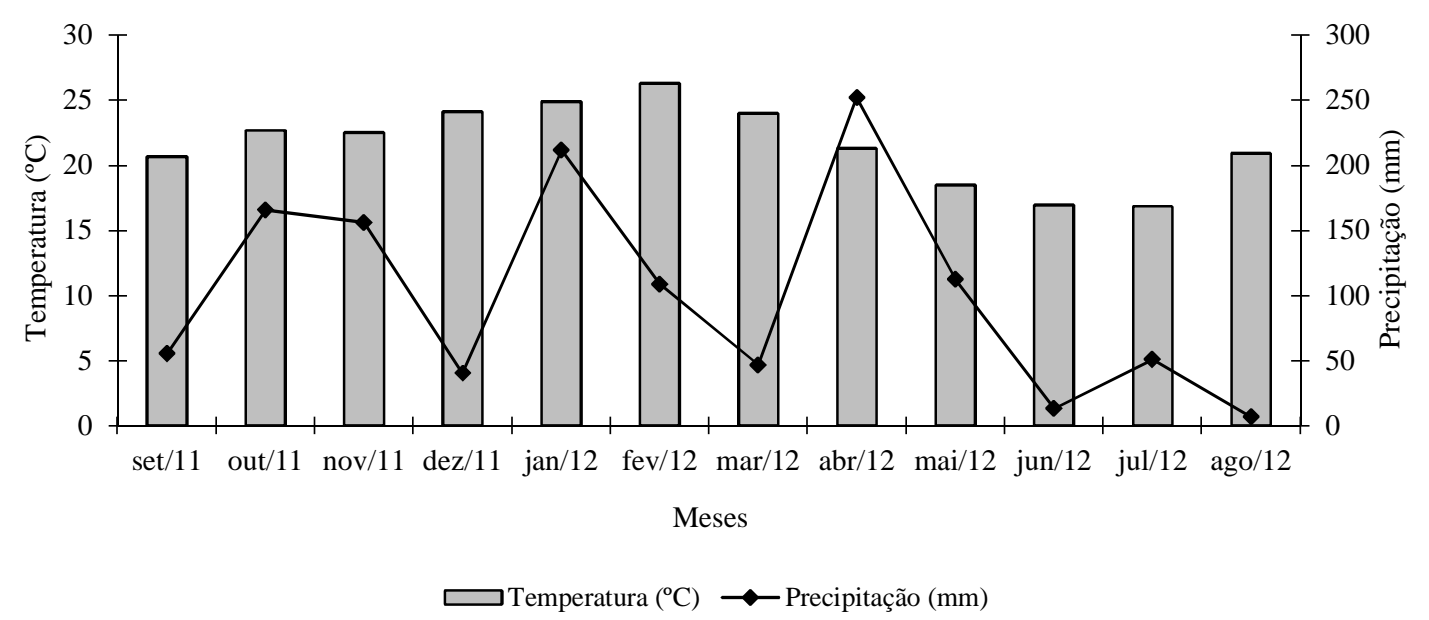

Figura 1. Médias de temperatura $\left({ }^{\circ} \mathrm{C}\right)$ e de precipitação $(\mathrm{mm})$ durante o período de condução do experimento. Porto Mendes/PR, 2011-2012.

As aplicações dos tratamentos foram realizadas em 23/11/2011 em condição de solo seco e as plantas de mandioca apresentavam de 12 a 15 folhas, com altura média de $22,5 \mathrm{~cm}$. Foi utilizado um pulverizador costal, pressurizado a $\mathrm{CO}_{2}$ e munido de barra com quatro pontas de jato plano (Modelo Jacto 110LD-02), espaçados entre si de $50 \mathrm{~cm}$, sendo o consumo de calda equivalente a $200 \mathrm{~L} \mathrm{ha}^{-1}$, utilizando-se a pressão de $48 \mathrm{Lb}$ pol$^{-2}$. As aplicações foram realizadas no final da tarde, sendo que no momento da aplicação as condições de temperatura, umidade relativa do ar e velocidade do vento foram $28,1^{\circ} \mathrm{C}, 63,0 \%$ e $2,1 \mathrm{~km} \mathrm{~h}^{-1}$, respectivamente.

As avaliações de fitointoxicação na mandioca foram realizadas de forma visual, utilizando-se uma escala de percentual de notas, em que 0 (zero) correspondeu a nenhuma injúria demonstrada pela planta de mandioca e 100 (cem) à morte das plantas de mandioca (SBCPD, 1995). Os critérios usados para o estabelecimento das notas foram: inibição do crescimento, quantidade e uniformidade das injúrias, capacidade de rebrota das plantas e quantidade de plantas mortas. As avaliações foram realizadas aos 7 , 12, 20, 26, 33 e 43 dias após a aplicação dos herbicidas (DAA). Aos 43 DAA, foram avaliadas cinco plantas ao acaso nas três linhas centrais das parcelas para a determinação da altura (m). A avaliação foi realizada utilizandose uma régua graduada $(2 \mathrm{~m})$ medindo-se a planta a partir do solo até o ápice. Por ocasião da colheita das raízes da mandioca (16/08/2012 - ciclo de 11 meses) coletaram-se as plantas das três linhas centrais das parcelas, desconsiderando uma planta de cada extremidade das linhas. Após a pesagem das raízes, determinou-se a produtividade $\left(\mathrm{t} \mathrm{ha}^{-1}\right)$. Foram coletadas de cada parcela uma amostra de $5,0 \mathrm{~kg}$ de raízes, para a determinação da porcentagem e rendimento $\left(\mathrm{t} \mathrm{ha}{ }^{-1}\right)$ de fécula utilizando-se o método da balança hidrostática conforme proposto por Grossman \& Freitas (1950).

Os resultados de altura, produtividade de raízes de porcentagem e rendimento de fécula foram submetidos à análise de variância pelo teste $\mathrm{F}$, e suas médias comparadas pelo teste Tukey a $5 \%$ de probabilidade.

\section{Resultados e Discussão}

Com relação a fitointoxicação dos herbicidas sobre a mandioca 'Cascuda', apenas o mesotrione com óleo mineral apresentou sintomas de injúrias nas plantas, com médias de 26,3 e $36,3 \%$, para as concentrações de 0,5 e $1,0 \%\left(\mathrm{v} \mathrm{v}^{-1}\right)$ do adjuvante, respectivamente aos 
7 DAA (Tabela 1). As injúrias causadas pelo mesotrione ocorreram principalmente nas folhas novas que apresentaram amarelecimento de todo o limbo foliar, enquanto que em algumas folhas do terço médio da planta ocorreu amarelecimento nas margens do limbo com posterior necrose e formação de áreas encarquilhadas. Entretanto, os sintomas de danos desapareceram completamente a partir dos 43 DAA. Este fato evidencia que a utilização do óleo mineral com o mesotrione promoveu incrementos na penetração cuticular e na absorção do ingrediente ativo, o que reduziu a tolerância das plantas de mandioca 'Cascuda' ao herbicida, corroborando com as hipóteses do trabalho. Portanto, a recomendação da utilização de adjuvantes em aplicações de herbicidas deve ser feita criteriosamente, uma vez que, dependendo do herbicida a ser utilizado pode ocorrer fitointoxicação e redução da tolerância da cultura a moléculas consideradas seletivas.

Tabela 1. Fitointoxicação (\%) após a aplicação em pós-emergência de herbicidas com diferentes concentrações de óleo mineral na cultura da mandioca 'Cascuda'. Porto Mendes/PR, 2011-2012.

\begin{tabular}{|c|c|c|c|c|c|c|c|c|}
\hline \multirow{2}{*}{$\begin{array}{c}\text { Nome } \\
\text { comum }\end{array}$} & \multirow{2}{*}{$\begin{array}{c}\text { Dose } \\
\left(\mathrm{g} \mathrm{ha}^{-1}\right)\end{array}$} & \multirow{2}{*}{$\begin{array}{c}\text { Óleo } \\
\%\left(\mathrm{v} \mathbf{v}^{-1}\right)\end{array}$} & \multicolumn{6}{|c|}{ Dias Após a Aplicação (DAA) } \\
\hline & & & 7 & 12 & 20 & 26 & 33 & 43 \\
\hline \multirow{3}{*}{$\begin{array}{l}\text { clethodim } \\
\text { (Accase) }\end{array}$} & \multirow{3}{*}{120} & 0,0 & 0,0 & 0,0 & 0,0 & 0,0 & 0,0 & 0,0 \\
\hline & & 0,5 & 0,0 & 0,0 & 0,0 & 0,0 & 0,0 & 0,0 \\
\hline & & 1,0 & 0,0 & 0,0 & 0,0 & 0,0 & 0,0 & 0,0 \\
\hline \multirow{3}{*}{$\begin{array}{c}\text { fluazifop-p- } \\
\text { butyl } \\
\text { (Accase) }\end{array}$} & \multirow{3}{*}{250} & 0,0 & 0,0 & 0,0 & 0,0 & 0,0 & 0,0 & 0,0 \\
\hline & & 0,5 & 0,0 & 0,0 & 0,0 & 0,0 & 0,0 & 0,0 \\
\hline & & 1,0 & 0,0 & 0,0 & 0,0 & 0,0 & 0,0 & 0,0 \\
\hline \multirow{3}{*}{$\begin{array}{l}\text { mesotrione } \\
\text { (Caroteno) }\end{array}$} & \multirow{3}{*}{240} & 0,0 & 0,0 & 2,3 & 0,0 & 0,0 & 0,0 & 0,0 \\
\hline & & 0,5 & 26,3 & 33,0 & 10,5 & 6,3 & 0,0 & 0,0 \\
\hline & & 1,0 & 36,3 & 51,3 & 18,8 & 11,8 & 5,5 & 0,0 \\
\hline Testemunha & --- & --- & 0,0 & 0,0 & 0,0 & 0,0 & 0,0 & 0,0 \\
\hline
\end{tabular}

A recuperação da mandioca 'Cascuda' após a aplicação do mesotrione com óleo mineral possivelmente pode ser explicada pelas condições climáticas favoráveis ao desenvolvimento das plantas (Figura 1), pela a capacidade da planta em metabolizar o ingrediente ativo e pela a cultura apresentar ciclo relativamente longo. Vale ressaltar que a ocorrência de fitointoxicação elevada $(\geq 50,0 \%$ ) seguida de longos períodos de veranicos pode influenciar negativamente o início do desenvolvimento e a produtividade da cultura.

Sintomas de fitointoxicação de 15,0 a $27,5 \%$ aos 14 DAA, causada pelo mesotrione $\left(216 \mathrm{~g} \mathrm{ha}^{-1}\right)$ sem a adição de adjuvante foram observados nas cultivares de mandioca 'Cacau UFV', 'Platina', 'Coqueiro', 'Coimbra' e 'IAC-12', contudo as cultivares foram consideras tolerantes ao herbicida (Silveira et al., 2012). Estes resultados revelam que existe diferença na tolerância ao mesotrione entre as cultivares de mandioca, já que a 'Cascuda' apresentou sintomas de fintointoxicação inferior a 2,3\% aos 12 DAA, quando utilizou sem óleo mineral. A adição de adjuvantes Assist $^{\circledR}$ e Veget'Oil $^{\circledR}$ nas concentrações de 0,5 e $3,0 \% \quad \mathrm{v} \mathrm{v}^{-1}$, potencializou o efeito do mesotrione (168 $\mathrm{g} \mathrm{ha}^{-1}$ ) no controle de plantas de leiteiro (Euphorbia heterophylla), no estádio de duas folhas verdadeiras (Grigolli et al., 2011).

Oliveira Jr. et al. (2001), observaram que a mistura formulada de ametryne + clomazone $\left(2,5 \mathrm{~kg} \mathrm{ha}^{-1}\right)$ registrada para a cultura da mandioca, promoveu maiores sintomas de fitointoxicação aos 51 dias após o plantio nas cultivares 'Mico' e 'Fécula 
Branca', do que nas cultivares 'Espeto', 'IAC14' e 'Fibra'. Da mesma forma, Biffe et al. (2010) citaram que o uso de diuron (800 $\mathrm{g} \mathrm{ha}^{-1}$ ) deve ser criterioso, pois verificaram que existe diferença quanto à seletividade do herbicida entre as cultivares 'Fécula Branca' e 'Fibra', sendo esta última mais seletiva.

Os herbicidas não reduziram a altura das plantas de mandioca quando aplicados com o adjuvante óleo mineral, e comparados com a testemunha sem aplicação (Tabela 2).

Tabela 2. Altura (cm) de plantas da mandioca 'Cascuda' aos 43 dias após a aplicação em pósemergência de herbicidas com diferentes concentrações de óleo mineral. Porto Mendes/PR, 20112012.

\begin{tabular}{lcccc}
\hline \multicolumn{1}{c}{ Tratamentos } & Dose & \multicolumn{3}{c}{ Óleo \% $\left(\mathrm{v} \mathrm{v}^{-1}\right)$} \\
\cline { 3 - 5 } & $\left(\mathrm{g} \mathrm{ha}^{-1}\right)$ & 0,0 & 0,5 & 1,0 \\
\hline Clethodim & 120 & 93,65 & 78,3 & 91,75 \\
fluazifop-p-butyl & 250 & 91,20 & 89,8 & 93,50 \\
Mesotrione & 240 & 94,65 & 88,8 & 96,25 \\
\hline Testemunha & --- & & 86,9 & \\
\hline \hline QM $_{\text {Tratamentos }}$ & & $105,349^{\mathrm{ns}}$ \\
$\mathrm{QM}_{\text {Fatorial }}$ & & & $111,258^{\mathrm{ns}}$ & \\
$\mathrm{QM}_{\text {Contraste }}$ & & $58,081^{\mathrm{ns}}$ & \\
$\mathrm{QM}_{\text {Blocos }}$ & & & $84,812^{\mathrm{ns}}$ & \\
$\mathrm{CV}(\%)$ & & & 71,784 & \\
\hline
\end{tabular}

${ }^{\text {ns }}$ - não significativo.

Para produtividade de raízes, assim como porcentagem e rendimento de fécula, não foram constatadas houve reduções (Tabela 3). Nesses aspectos, destaca-se que mesmo após a aplicação de mesotrione + óleo mineral $\left(1,0 \% \mathrm{v} \mathrm{v}^{-1}\right)$ ter promovido até $51,3 \%$ de fitointoxicação aos 12 DAA, não ocorreram prejuízos na produção de raízes e fécula da mandioca 'Cascuda'. Contudo, o mesotrione tende a ser mais seletivo para mandioca 'Cascuda' quando aplicado sem a adição de óleo mineral e que caso haja a necessidade da utilização de óleo mineral para aumentar a eficiência no controle das plantas daninhas deve ser feita considerando a concentração a ser utilizada. Os resultados com mesotrione indicam a oportunidade da avaliação de outros adjuvantes e/ou mesmo de safeners na seletividade de herbicidas para cultura da mandioca.

De acordo com Abreu et al. (2010ab), o fluazifop (100 $\left.\mathrm{g} \mathrm{ha}^{-1}\right)$ não prejudicou a produtividade de raízes, o teor de amido e a porcentagens de raízes comerciais das variedades IAC14 e IAC576-70. O clethodim e o fluazifop são inibidores da enzima ACCase, mas apenas o clethodim possui registro de uso na cultura da mandioca no Brasil e a seletividade a 'Cascuda' já era esperada (Rodrigues \& Almeida, 2011). Com relação a alta seletividade apresentada a cultivar pelo fluazifop (250 $\mathrm{g} \mathrm{ha}^{-1}$ ) pode ser justificado devido o mecanismo de ação ser o mesmo do clethodim. Resultados semelhantes foram observados com a aplicação de fluazifop (250 g $\mathrm{ha}^{-1}$ ) em pós-emergência das plantas daninhas e cultivares de mandioca 'Cacau UFV', 'Platina', 'Coqueiro', 'Coimbra' e 'IAC-12' (Silva et al., 2011).

Ressalta-se que o uso de óleo mineral pode maximizar a eficiência dos clethodim e do fluazifop-p-butyl no controle das plantas daninhas na cultura da mandioca, conforme resultados obtidos por Velini et al. (2000b) que constataram maior eficácia do glyphosate (1.260 $\left.\mathrm{g} \mathrm{ha}^{-1}\right)$ no controle de Brachiaria 
decumbens e Panicum maximum com aumento da concentração do adjuvante Aterbane ${ }^{\circledR}$ na calda de aplicação. Da mesma maneira, a utilização dos adjuvantes Triunfo ${ }^{\circledR}$ $\left(0,04 \% \mathrm{v} \mathrm{v}^{-1}\right)$, Grap Super Gun ${ }^{\circledR}\left(0,25 \% \mathrm{v} \mathrm{v}^{-1}\right)$,
$\operatorname{Assist}^{\circledR}\left(0,04 \% \mathrm{v} \mathrm{v}^{-1}\right)$ e Fulltec $^{\circledR}\left(0,04 \% \mathrm{v} \mathrm{v} \mathrm{v}^{-1}\right)$, incrementaram significativamente $\quad 0$ desempenho do glyphosate $\left(1.080 \mathrm{~g} \mathrm{ha}^{-1}\right)$ na dessecação de pré-semeadura do trigo (Maciel et al., 2011).

Tabela 3. Produtividade, porcentagem e rendimento de fécula nas raízes da mandioca 'Cascuda' após a aplicação em pós-emergência de herbicidas com diferentes concentrações de óleo mineral. Porto Mendes/PR, 2011-2012.

\begin{tabular}{|c|c|c|c|c|c|c|c|c|c|c|}
\hline \multirow{3}{*}{ Tratamentos } & \multirow{3}{*}{$\begin{array}{c}\text { Dose } \\
\left(\mathrm{g} \mathrm{ha}^{-1}\right)\end{array}$} & \multicolumn{3}{|c|}{ Produtividade $\left(\mathrm{t} \mathrm{ha}^{-1}\right)$} & \multicolumn{3}{|c|}{ Fécula (\%) } & \multicolumn{3}{|c|}{$\begin{array}{l}\text { Rendimento de } \\
\text { Fécula }\left(\mathrm{t} \mathrm{ha}^{-1}\right)\end{array}$} \\
\hline & & \multicolumn{9}{|c|}{ Óleo \% $\left(\mathrm{v} \mathrm{v}^{-1}\right)$} \\
\hline & & 0,0 & 0,5 & 1,0 & 0,0 & 0,5 & 1,0 & 0,0 & 0,5 & 1,0 \\
\hline clethodim & 120 & 33,48 & 30,42 & 32,41 & 20,63 & 22,75 & 21,38 & 6,88 & 6,94 & 6,94 \\
\hline fluazifop-p-butyl & 250 & 30,40 & 31,45 & 29,62 & 21,25 & 21,38 & 21,63 & 6,50 & 6,73 & 6,41 \\
\hline mesotrione & 240 & 31,93 & 33,97 & 29,47 & 21,25 & 20,88 & 21,63 & 6,81 & 7,09 & 6,37 \\
\hline Testemunha & --- & & 30,64 & & & 21,13 & & & 6,47 & \\
\hline $\mathrm{QM}_{\text {Tratamentos }}$ & & & $9,641^{\mathrm{ns}}$ & & & $1,298^{\mathrm{ns}}$ & & & $0,262^{\text {ns }}$ & \\
\hline $\mathrm{QM}_{\text {Fatorial }}$ & & & $10,546^{\mathrm{ns}}$ & & &, $421^{\mathrm{ns}}$ & & & $0,262^{\mathrm{ns}}$ & \\
\hline $\mathrm{QM}_{\text {Contraste }}$ & & & $2,398^{\text {ns }}$ & & &, $306^{\mathrm{ns}}$ & & & $0,259^{\text {ns }}$ & \\
\hline $\mathrm{QM}_{\mathrm{Blocos}}$ & & & $20,829^{\text {ns }}$ & & & $2,806^{\mathrm{ns}}$ & & & $1,269^{\text {ns }}$ & \\
\hline $\mathrm{CV}(\%)$ & & & 13,02 & & & 9,82 & & & 15,47 & \\
\hline
\end{tabular}

ns - não significativo.

Portanto, a seleção de outros herbicidas seletivos a mandioca e que apresentam diferentes mecanismos de ação, a exemplo do mesotrine (Inibidor dos carotenoides), podem contribuir no manejo das plantas daninhas para a referida cultura e evitar a seleção de biótipos resistentes aos herbicidas (Beckie et al., 2004; Mello et al., 2012).

\section{Conclusões}

Os herbicidas clethodim (120 $\left.\mathrm{g} \mathrm{ha}^{-1}\right)$, fluazifop-p-butyl (250 $\left.\mathrm{g} \mathrm{ha}^{-1}\right)$ e mesotrione (240 $\left.\mathrm{g} \mathrm{ha}^{-1}\right)$ apresentaram-se seletivos a cultura da mandioca 'Cascuda', quando aplicados em pós-emergência na presença ou ausência de óleo mineral Assist ${ }^{\circledR}$ até $1 \% \mathrm{v} \mathrm{v}^{-1}$. Entretanto, o mesotrione promoveu sintomas de fitointoxicação leves a moderados, quando aplicado com óleo mineral.

\section{Agradecimentos}

Agradecemos ao Instituto Agronômico do Paraná (IAPAR) e a Associação Técnica das Indústrias de Mandioca do Paraná (ATIMOP) pelo apoio técnico destinado para a realização deste trabalho de pesquisa.

\section{Referências}

ABREU, M.L. et al. Efeitos das alternativas de herbicidas aplicados em nível comercial na cultura da mandioca no balanço de massa final das raízes. Revista Raízes e Amidos Tropicais, v.6, n.1, p.77-82, 2010a.

ABREU, M.L. et al. Efeito de diferentes herbicidas aplicados na cultura da mandioca na quantidade qualidade de raízes comerciais. Revista Raízes e Amidos Tropicais, v.6, n.1, p.66-76, $2010 b$.

ALABI, B.S. et al. Giant sensitiveplant interference in cassava. Weed Science, v.49, n.2, p.171-176, 2001.

ALBUQUERQUE, J.A.A. et al. Interferência de plantas daninhas sobre a produtividade da mandioca (Manihot esculenta). Planta Daninha, v.26, n.2, p.279-289, 2008.

BECKIE, H.J. et al. Multiple herbicideresistant canola can be controlled by alternative 
herbicides. Weed Science, v.52, n.1, p.152157, 2004.

BIFFE, D.F. et al. Avaliação de herbicidas para dois cultivares de mandioca. Planta Daninha, v.28, n.4, p.807-816, 2010.

BUICK, R.D.; BUCHAN, G.D.; FIELD, R.J. The role of surface tennsion of spreading droplets in absorption of a herbicide formulation via leaf stomata. Pesticide Science, v.38, n.2-3, p.227-235, 1993.

CHIKOYE, D. et al. Options for Cogongrass (Imperata cylindrica) Control in White Guinea Yam (Dioscorea rotundata) and Cassava (Manihot esculenta). Weed Technology, v.20, n.3, p.784-792, 2006.

CHIKOYE, D.; EKELEME, F.; UDENSI, U.E. Cogongrass suppression by intercropping cover crops in corn/cassava systems. Weed Science, v.49, n.5, p.658-667, 2001.

DORETTO, M. Distribuição da cultura da mandioca no Paraná nos anos 80. Londrina: IAPAR, 1993. 19p. (Informe de Pesquisa, 102).

FAO - FOOD AND AGRICULTURE ORGANIZATION OF THE UNITED NATIONS. Final 2009 Data Now Available: FAOSTAT. Disponível em: $<$ http://faostat.fao.org/site/567/DesktopDefault. aspx?PageID=567\#ancor $>$. Acesso em: $24 \mathrm{de}$ jul. 2011.

FELIPE, F.I.; ALVES, L.R.A.; CAMARGO, S.G.C. Panorama e perspectivas para a indústria de fécula de mandioca no Brasil. Revista Raízes e Amidos Tropicais, v.6, n.1, p.134-146, 2010.

GRIGOLLI, J.F.J. et al. Controle de Euphorbia heterophylla com mesotrione e óleos para diferentes pontas de pulverização. Revista Brasileira de Herbicidas, v.10, n.3, p.266276, 2011.

GROSMAN, J.; FREITAS, A.C. Determinação do teor de matéria seca pelo peso específico em raízes de mandioca.
Revista Agronômica, v. 14, n. 160/162, p. 7580, 1950.

IBGE - INSTITUTO BRASILEIRO DE GEOGRAFIA E ESTATÍSTICA. Levantamento Sistemático da produção Agrícola: pesquisa mensal de previsão e acompanhamento das safras agrícolas no ano civil. Fundação Instituto Brasileiro de Geografia e Estatística. - Dezembro, 2012. Rio de Janeiro, v.25, n. 12, p.1-84, 2012.

JOHANNS, O.; CONTIERO, R.L. Efeitos de diferentes períodos de controle e convivência de plantas daninhas com a cultura da mandioca. Revista Ciência Agronômica, v.37, n.3, p.326-331, 2006.

MACIEL， C.D.G.; MORAES， D.W.M.; BALAN, M.G. Associação de adjuvantes com herbicidas na dessecação e no controle em pósemergência de plantas daninhas na cultura do trigo. Revista Brasileira de Herbicidas, v.10, n.3, p.243-256, 2011.

MACIEL, C.D.G. et al. Tensão superficial estática de misturas em tanque de glyphosate+ chlorimuron-ethyl isoladas ou associadas com adjuvantes. Planta Daninha, v.28, n.3, p.673685, 2010.

MELLO, M.S.C. et al. Alternativas para o controle químico de capim-amargoso (Digitaria insularis) resistente ao glyphosate. Revista Brasileira de Herbicidas, v.11, n.2, p.195-203, 2012.

MENDONÇA， C.G.; RAETANO， C.G.; MENDONÇA, C.G. Tensão superficial estática de soluções aquosas com óleos minerais e vegetais utilizados na agricultura. Engenharia Agrícola, v.27, n.esp., p.16-23, 2007.

OLIVEIRA JR., R.S. et al. Tolerância de cinco cultivares de mandioca (Manihot esculenta) a herbicidas. Planta Daninha, v.19, n.1, p.119125, 2001.

PERESSIN, V.A. et al. Acúmulo de matéria seca na presença e na ausência de plantas infestantes no cultivar de mandioca SRT59 - 
Branca de Santa Catarina. Bragantia, v.57, n.1, p.135-148, 1998.

RODRIGUES, B.N.; ALMEIDA, F.S. Guia de herbicidas. 6.ed. Londrina: 2011. 697 p.

SAGRILO, E. et al. Efeito da época de colheita no crescimento vegetativo, na produtividade e na qualidade de raízes de três cultivares de mandioca. Bragantia, v.61, n.2, p.115-125, 2002

SILVA, D.V. et al. Tolerância de cultivares de mandioca aos herbicidas fomesafen $\mathrm{e}$ fluazifop-p-butil. Revista Brasileira de Herbicidas, v.10, n.3, p.219-231, 2011.

SILVA, D.V. et al. Manejo de plantas daninhas na cultura da mandioca. Planta Daninha, v.30, n.4, p.901-910, 2012.

SILVA, F.M.L. et al. Moléculas de herbicidas seletivos à cultura da mandioca. Revista Trópica: Ciências Agrárias e Biológicas. v.3, n.2, p.61-72, 2009.

SILVA, J.R.; CHABARIBERY, D. Coeficientes técnicos e custo de produção da mandioca para mesa na região de Mogi-Mirim, Estado de São Paulo. Informações Econômicas, v.36, n.1, p.26-32, 2006.

SILVEIRA, H.M. et al. Sensibilidade de cultivares de mandioca ao herbicida mesotrione. Revista Brasileira de Herbicidas, v.11, n.1, p.24-31, 2012.

SINGH, M.; MACK, R.E. Effect of organosilicone- based adjuvants on herbicide efficacy. Pesticide Science, v.38, n.2-3, p.219225, 1993.

SOCIEDADE BRASILEIRA DA CIÊNCIA DAS PLANTAS DANINHAS - SBCPD. Procedimentos para instalação, avaliação e análise de experimentos com herbicidas. Londrina: $1995.42 \mathrm{p}$.

SOUZA, R.T.; VELINI, E.D.; PALLADINI, L.A. Aspectos metodológicos para análise de depósitos de pulverizações pela determinação dos depósitos pontuais. Planta Daninha. v.25, n.1, p.195-202, 2007

STOCK, D.; HOLlOWAY, P.J. Possible mechanisms for surfactant- induced foliar uptake of agrochemicals. Pesticide Science, v.38, n.2-3, p.165-177, 1993.

VELINI, E.D. et al. Avaliação da seletividade da mistura de oxyfluorfen e ametryne, aplicada em pré ou pós-emergência, a dez variedades de cana-de-açúcar (cana-planta). Planta Daninha, v.18, n.1, p.123-134, 2000a.

VELINI, E.D.; MARTINS, D.; SILVA, M.A.S. Efeito de concentrações de espalhante adesionante e doses de glyphosate no controle de Brachiaria decumbens e Panicum maximum. Planta Daninha, v.18, n.2, p.349366. $2000 \mathrm{~b}$. 